ISSN. 2621-9832

JURNAL MathEdu (Mathematic Education Journal)

http://journal.ipts.ac.id/index.php/MathEdu

Vol. 4 No. 2 Juli 2021

\title{
EKSPLORASI ETNOMATEMATIKA PADA RUMAH ADAT MANUNIS KA'UMNAIS SUKU UIM BIBUIKA KECAMATAN BOTIN LEOBELE, KABUPATEN MALAKA
}

\author{
Anita Mar ${ }^{(1)}$, Oktovianus Mamoh ${ }^{(2)}$, Stanislaus Amsikan ${ }^{(3)}$ \\ 1,2,3 Program Studi Pendidikan Matematika, Fakultas Ilmu Pendidikan, Universitas Timor, Email: \\ maranita911@gmail.com \\ Email: oktomamoh01@gmail.com \\ Email: amssta.ika@gmail.com
}

\begin{abstract}
ABSTRAK
Budaya merupakan kebiasaan masyarakat yang terjadi secara turun temurun yang menjadi identitas dari suatu daerah. Salah satu yang menjembatani pendidikan dan budaya khususnya pendidikan matematika adalah etnomatematika. Etnomatematika merupakan ilmu yang menghubungkan soal kebudayaan yang terdapat pada suatu suku atau daerah dengan unsur matematika. Tujuan penelitian ini adalah mengeksplorasi konsepkonsep matematika yang terdapat pada uim re'u Manunis Ka'umnais. penelitian ini merupakan penelitian kualitatif dengan pendekatan etnografi. Penelitian dilaksanakan di Desa Babotin, Kecamatan Botin Leobele, Kabupaten Malaka, pada tanggal 19 September 2020. Subjek penelitian ini adalah informan yaitu kepala suku. Instrumen penelitian berupa human instrument, pedoman observasi, pedoman wawancara dan dokumentasi. Analisis data dilakukan melalui tiga tahap yaitu reduksi data, display data dan penarikan kesimpulan. Hasil penelitian ini menunjukkan bahwa unsur-unsur bangunan seperti tiang, dinding dan atap dari uim re'u Manunis Ka'umnais memuat konsep-konsep matematika yang terdapat pada materi geometri seperti titik, garis, bangun datar, bangun ruang, kesebangunan, dan transformasi geometri (refleksi).
\end{abstract}

\section{Kata Kunci: Eksplorasi, Etnomatematika, Uim Re'u Manunis Ka'umnais}

\section{ABSTRACK}

Culture is a community habit that occurs from generation to generation which becomes the identity of an area. One that bridges education and culture especially mathematics education is ethnomatematics. Ethnomatematics is a science that connects cultural problems contained in a tribe or area with mathematical elements. The purpose of this study is to explore the mathematical concepts contained in uim re'u Manunis Ka'umnais. This research is qualitative research with an ethnographic approach. The research was conducted in Babotin Village, Botin Leobele District, Malaka Regency, on 19 September 2020. The subject of this research is the informant, namely the chief of the tribe. Research instruments in the form of human instruments, observation guidelines, interview guidelines and documentation. Data analysis was carried out in three stages, namely data reduction, data display and conclusion drawing. The result of this study indicate that building elements such as poles, walls and roofs from uim re'u Manunis Ka'umnais contain mathematical concepts contained in geometric materials such as points, lines, shapes, similarities, and geometric transformations (reflection).

\section{Keywords: Exploration, Ethnomatematics, Uim Re'u Manunis Ka'umnais}

\section{PENDAHULUAN}

Pendidikan dan budaya merupakan dua komponen yang tidak terpisahkan seperti dua sisi pada mata uang. Budaya merupakan kebiasaan masyarakat yang terjadi secara turun temurun yang menjadi identitas dari suatu daerah. Menurut (Ratna 2005: 5) budaya merupakan keseluruhan aktivitas manusia, termasuk pengetahuan, kepercayaan, seni, moral, hukum, adat-istiadat dan kebiasaan-kebiasaan lain. Sedangkan pendidikan merupakan kebutuhan yang hakiki dari masyarakat karena selama manusia hidup manusia akan terus belajar (long life education). Daoed Joesoef (Putri, 2017: 25) menyatakan bahwa kebudayaan diartikan sebagai semua hal yang terkait dengan budaya. Artinya apapun itu namanya, macamnya, maupun isinya dari suatu kebiasaan masyarakat yang terkait dengan budaya disebut dengan kebudayaan. Pendidikan sebagai produk budaya selalu berupaya agar pendidikan ada keterkaitan antara matematika dan budaya. Salah satu alternatif yang dapat mengaitkan budaya dengan matematika yaitu etnomatematika. 
Wahyuni et.al (2013: 2) mengatakan bahwa salah satu yang dapat menjembatani pendidikan dan budaya khususnya pendidikan matematika adalah etnomatematika. Tanpa disadari masyarakat telah melakukan berbagai aktivitas dengan menggunakan konsep dasar matematika dan ide-ide matematis. Kabupaten Malaka merupakan salah satu kabupaten di propinsi Nusa Tenggara Timur yang memiliki beragam kebudayaan daerah yang memiliki ciri khas sehingga menjadikannya sedikit berbeda dari daerah lainnya. Selain itu ada yang menarik dari kebudayaan di Malaka, yaitu rumah adat yang berbentuk Panggung dan diberi nama rumah adat Manunis Ka'umnais. Dalam arsitektur bangunan rumah adat Manunis Ka'umnais tersebut terdapat unsur-unsur bangunan seperti rumah adat pada umumnya.

Unsur-unsur bangunan yang dimaksud seperti atap, tiang, jendela, pintu, dan lain-lain. Pada unsur bangunan rumah adat Manunis Ka'umnais ditemukan bentuk-bentuk yang sama dengan bentuk geometri pada pembelajaran matematika. Artinya dalam rumah adat Manunis Ka'umnais, banyak ditemukan konsep geometri yang merupakan salah satu konsep matematika sehingga tanpa disadari dalam budaya rumah adat Manunis Ka'umnais secara tidak langsung, masyarakat sudah menerapkan konsep matematika dalam konstruksi bangunannnya. Sehingga mempelajari matematika menjadi satu kesatuan dengan kebudayaan yang dimiliki oleh mayarakat setempat. Masyarakat selama ini menganggap bahwa matematika tidak berkaitan dengan kehidupan sehari-hari serta sangat tidak relevan dengan budaya. Tanpa disadari bahwa kebudayaan lokal yang telah ada sejak dahulu sebelum masyarakat mengenal lebih dalam tentang matematika sudah ada konsep matematika didalamnya. Sehingga terbukti matematika tidak dapat dipisahkan dengan kebudayaan daerah setempat.

Berbagai penelitian dalam mengeksplorasi etnomatematika pada masyarakat telah dilakukan, seperti pada penelitian Amsikan \& Nahak (2017) bahwa fakta tentang ruang dan unsur-unsur yang tidak didefinisikan pada struktur arsitektur Ume Kbubu desa Kaenbaun Kabupaten Timor Tengah Utara misalnya titik, garis, sudut merupakan konsep geometri yang dapat dieksplorasi untuk kegiatan pembelajaran matematika disekolah. Penelitian Funan \& Mamoh (2019) yang mengeksplorasi etnomatematika Uem Le'u Insana dalam kaitannya dengan konsep geometri yang terkandung dalam bentuk uem le'u antara lain titik, garis, sudut, bangun datar dan bangun ruang. Selanjutnya hasil penelitian Deda \& Amsikan (2019) bahwa terdapat motif kain tenun di kefamenanu - TTU (Motif Buna, Futus dan Mapauf) yang mengandung kearifan lokal dan dapat digunakan untuk memperkenalkan konsep geometri seperti refleksi, rotasi, translasi dan pengulangan serta dapat digunakan untuk memahami sifat-sifat segitiga dan segiempat, serta luas segiempat dalam matematika.

Konsep etnomatematika memberikan kontribusi yang besar terhadap peningkatan pembelajaran matematika, karena mengaitkan dengan pengalaman siswa dalam kehidupan sehari-hari yang menyentuh ranah seni budaya daerah setempat sehingga siswa menjadi lebih memahami konsep matematika yang dijelaskan. Dengan demikian sebagai calon pendidik matematika menurut Rino Richardo (2016: 1-38) perlu memahami bahwa untuk meningkatkan pemahaman matematika dapat mempraktekkan atau menjelaskan konsep matematika dengan menggunakan pendekatan etnomatematika.

\section{TINJAUAN PUSTAKA Etnomatematika}

Menurut Ascher (Tandililing, 2015: 40) etnomatematika merupakan satu kajian yang dibuat ke atas ideaidea matematika masyarakat tradisional. Etnomatematika juga merupakan suatu kajian tentang pengaplikasian matematika yang digunakan untuk mengenal pasti sebuah kumpulan budaya, dari aspek yang membincangkan masalah persekitaran dan aktivitas dari kumpulan-kumpulan budaya tersebut.

Pada tahun 1999 D'Ambrosio menggunakan kata etnomatematika sebagai mode, gaya dan teknik dalam memahami, menjelaskan dan dalam menghadapi lingkungan alam dan budaya dalam suatu sistem budaya yang berbeda, seperti yang dijelaskan oleh D'Ambrosio (Rachmawati, $2012: 4)$ "I have been using the word ethnomatematics as modes, styles, and techniques (tics) of explanation, of understanding, and coping with the natural and curturalenvirontment (mathema) in distinct cultural systems (ethno)". Artinya "'saya telah menggunakan kata etnomatematika sebagai mode, gaya dan teknik (tics) menjelaskan, memahami dan menghadapi lingkungan alam dan budaya (mathema) dalam sistem budaya yang berbeda (ethnos) '.

Sejalan dengan gagasan diatas Rachmawati (2012: 1) mengatakan bahwa aktivitas matematika adalah aktivitas yang di dalamnya terjadi proses pengabstraksian dari pengalaman nyata dalam kehidupan sehari-hari kedalam matematika atau sebaliknya, meliputi aktivitas mengelompokkan, berhitung, mengukur, merancang bangunan atau alat, membuat pola membilang, menentukan lokasi, bermain, menjelaskan dan lain sebagainya.

Rumah adat adalah kelengkapan yang digunakan atau ditempati oleh masyarakat tertentu (khususnya di Indonesia) yang menunjukkan etos kebudayaan masyarakat Indonesia. 
Rumah adat adalah kelengkapan yang digunakan atau ditempati oleh masyarakat tertentu (khususnya di Indonesia) yang menunjukkan etos kebudayaan masyarakat Indonesia. Bentuk rumah tersebut bermacam-macam sesuai dengan daerah yang ada di Indonesia.

Rumah adat pada dasarnya berguna untuk menutupi atau melindungi manusia dari kondisi lingkungan sekitar yang cenderung berbahaya, baik pelindung dari terik maupun dari dingin yang mencekam, selain itu pengamanan jasmaniah, terdapat pula fungsi-fungsi menurut pesan-pesan nilai budaya yang terkandung di dalam rumah adat Indonesia, yang berkaitan pula dengan aspek-aspek lain dari kehidupan berkebudayaan. Pemahaman nilai budaya yang dipesankan itu biasanya lahir melalui simbol-simbol dari berbagai macam hias rumah adat Indonesia dari suatu masyarakat.

Oleh karena itu salah satu adat yang dipilih oleh pneliti dalam melakukan penelitian dengan tujuan untuk mengeksplorasi konsep-konsep matematika adalah rumah adat Manunis Ka'umnais. Rumah adat Manunis Ka'umnais adalah salah satu rumah adat yang pertama kali dikenal oleh masyarakat Malaka khususnya Lo'oneke. Lokasi Rumah adat Manunis Ka'umnais terletak disebuah kampung kecil yaitu Uimtatoen, yang berada di Kabupaten Malaka, Kecamatan Botin Leobele, Desa Babotin, Dusun Lo'oneke C, RT/001, RW/001.

Masyarakat di daerah Malaka khususnya "Dawan R" (Manlea) menyebut rumah adat dengan istilah uim re'u. Kata uim re'u diambil dari istilah "Dawan R" yakni uim atau umi yang berarti rumah, dan kata re'u yang berarti keramat, pemali, suci, atau secara umum disebut adat. Jadi secara garis besar uim re'u artinya rumah adat.

\section{Karakteristik Matematika}

Matematika pada dasarnya terbentuk dari pengalaman manusia dalam dunianya secara empiris. Kemudian pengalaman itu diproses di dalam dunia rasio, diolah secara analisis dengan penalaran di dalam struktur kognitif sehingga sampai terbentuk konsep-konsep matematika. Konsep-konsep matematika yang terbentuk itu agar mudah dipahami oleh orang lain dan dapat dimanipulasi secara tepat, maka digunakan bahasa matematika atau notasi matematika yang bernilai global (universal). Konsep matematika didapat karena proses berpikir yang logis, karena itu logika merupakan dasar terbentuknya matematika.

Susanto (Funan dan Mamoh, 2019: 11) mendefinisikan matematika sebagai pengetahuan tentang fakta-fakta kuantitatif, masalah tentang ruang dan bentuk, serta struktur-struktur yang logis. Lebih lanjut, Susanto menjelaskan bahwa matematika adalah objek yang ditemukan dan diciptakan manusia, serta muncul dari aktivitas yang objeknya telah tersedia. Hal ini menjelaskan bahwa matematika lahir dan berkembang dalam masyarakat oleh fakta-fakta logis yang terjadi dalam masyarakat, dan matematika ditemukan atas dasar penalaran terhadap objek-objek yang ada dalam kehidupan. Singkatnya matematika tidak lahir dengan sendirinya melainkan ditemukan atau diciptakan.

Matematika sering dideskripsikan dengan cara yang berbeda-beda tergantung dari sudut pandang mana yang dipakai baik secara umum maupun secara khusus. Menurut Hudojo (Hasratuddin, 2014: 30) matematika merupakan ide-ide abstrak yang diberi simbol-simbol itu, tersusun secara hirarkis dan penalaran deduktif, sehingga belajar matematika itu merupakan kegiatan mental yang tinggi. Sedangkan menurut James dalam kamus matematikanya (Hasratuddin, 2014: 30) matematika adalah ilmu tentang logika mengenai bentuk, susunan, besaran dan konsep-konsep berhubungan lainnya dengan jumlah yang banyak yang terbagi ke dalam tiga bidang, yaitu aljabar, analisis dan goemetri. Matematika adalah ilmu yang mempelajari tentang kuantitas, fakta tentang bentuk, struktur, ruang yang logis dan sistematis. Matematika dikenal sebagai ilmu dedukatif, karena setiap metode yang digunakan dalam mencari kebenaran adalah dengan menggunakan metode deduktif. Beberapa deskripsi matematika yang sering dipergunakan (Sumardyono, 2004: 28) diantaranya ialah:

1. Matematika sebagai struktur yang terorganisir

2. Matematika sebagai alat (tool)

3. Matematika sebagai pola pikir deduktif

4. Matematika sebagai cara bernalar (the way of thinking)

5. Matematika sebagai bahasa artifisial

6. Matematika sebagai seni yang kreatif

\section{METODE PENELITIAN}

Jenis penelitian yang digunakan adalah penelitian kualitatif dengan pendekatan etnografi. Instrumen penelitian adalah alat atau fasilitas yang digunakan oleh peneliti dalam mengumpulkan data agar pekerjaannya 
lebih mudah dan hasilnya lebih baik, dalam arti lebih cermat, lengkap dan sistematis sehingga lebih mudah diolah, Arikunto (Munawwaroh, 2016: 31). Pada penelitian ini instrumen yang digunakan adalah sebagai berikut :

1. Instrumen Utama

Instrumen yang paling utama dalam penelitian ini adalah peneliti

2. Instrumen Pendukung

Instrumen pendukung dalam penelitian ini adalah :

a. Pedoman observasi

b. Pedoman wawancara

c. Dokumentasi

Teknik pengumpulan data dalam penelitian ini adalah sebagai berikut:

a. Observasi

b. Wawancara

c. Dokumentasi

Prosedur penelitian merupakan uraian mengenai langkah-langkah yang akan dilakukan sebagai pedoman untuk melaksanakan penelitian. Indrawati (Munawwaroh, 2016: 28) membagi tahapan penelitian kualitatif dalam tiga tahap yakni: tahap persiapan, tahap pelaksanaan, dan tahap pengolahan data.

Penelitian ini menggunakan teknik analisis data deskriptif kualitatif. Deskriptif kualitatif adalah pengolahan data dalam bentuk kata-kata bukan berupa data statistik. Analisis data kualitatif dalam penelitian ini adalah analisis data hasil dari wawancara yang dilakukan pada saat pendahuluan sampai akhir kegiatan penelitian. Adapun tahap-tahap analisis data dalam penelitian ini adalah sebagai berikut :

1. Reduksi data

2. Penyajian data

3. Penarikan Kesimpulan

\section{HASIL DAN PEMBAHASAN}

Berdasarkan hasil penelitian pada rumah adat (uim re'u) Manunis Ka'umnais bagian-bagian yang diteliti dari uim re'u sebagai berikut:

\section{Atap}
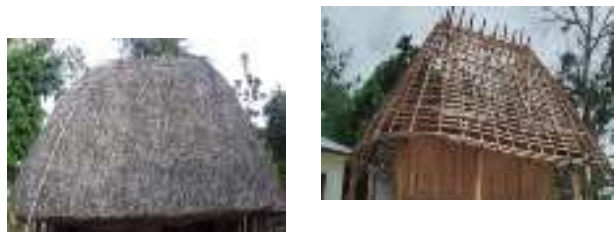

Gambar 1. Atap Uim Re'u

Masyarakat desa Babotin menggunakan bagian atap rumah adat berbentuk limas segiempat yang bentuknya menyerupai bentuk trapesium. Hal ini didasarkan pada bahan pembuatannya, seperti bentuk limas segiempat menggunakan daun gewang. Bentuk atap masih tradisional karena menggunakan bahan alam seperti daun gewang untuk mengatap. Pembuatan atap dibentuk dengan terlebih dahulu menghitung Panjang suaf dan tanpani yang akan digunakan untuk membuat rangka atap. Pembentukan atap didasarkan pada pengukuran suaf dan tanpani yang disesuaikan dengan tinggi dinding dan tinggi tiang tengah.

Pada atap, suaf rumah adat Manunis Ka'umnais masih menggunakan alat ukur tradisional yakni tali dan jengkalan tangan. Tali tersebut diukur dengan menngunakan jengkalan tangan, untuk menentukan 1 meter adalah 5 jengkalan tangan, sehingga 5 meter adalah 25 jengkalan tangan. Panjang suaf 5 meter yakni dari puncak uim re'u sampai tiris (pembuangan). Panjang tiris pada atap tidak menentu karena bahan atap yang digunakan adalah tain tuni (daun gewang) yang tidak beraturan. Suaf dipasang pada 24 titik sebagai suaf utama kemudian dipasang suaf pelengkap untuk memenuhi rangka atap uim re'u. Setelah pemasangan suaf selesai, langkah selanjutnya adalah pemasangan tanpani. Bahan dasar tanpani pada atap adalah kayu yang dapat di putar untuk membentuk pola melingkar pada rangka atap seperti kayu tabako dan koknaba. Pemasangan tanpani dimulai dari bagian bawah rangka atap (tiris/pembuangan) kemudian dilanjutkan 
kebagian atas hingga sampai puncak, dengan bentuk pola tanpani semakin keatas semakin kecil. Jarak antar tanpani berkisar $\pm 15-20 \mathrm{~cm}$.

\section{Dinding}

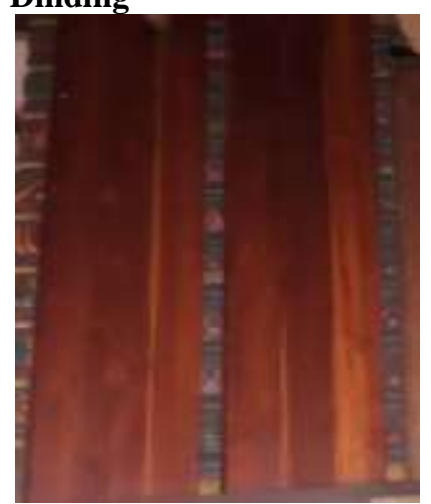

Gambar 2. Dinding

Dinding pada uim re'u menggunakan kayu papan yang disusun secara vertikal menutupi seluruh bagian uim re'u dengan panjang tiap papan 2 meter. Tiap-tiap papan saling berhimpit untuk membentuk satu sisi dinding yang dibatasi oleh tiang penjepit papan. Tiang penjepit papan (kentikaf) berjumlah 21 sesuai dengan seluruh dindingnya.

3. Tiang
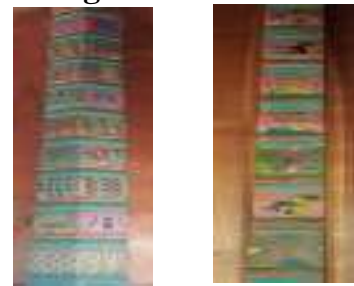

Gambar 3. Tiang kentikaf

Pada tiang penjepit papan (kentikaf) terdapat ukiran dengan bermacam-macam dari bentuk ukiran tersebut. Pertama, ukiran hewan pada kentikaf yakni anjing, ayam dan semut dengan makna budaya sebagai penyelamat waktu musim kekeringan.

Berdasarkan hasil wawancara konon katanya hewan-hewan pada ukiran tersebutlah yang menyelamatkan masyarakat suku uim Bibuika. Salah satunya yaitu ukiran hewan anjing yang berhasil mengatasi kekeringan pada waktu itu, dengan cara anjing tersebut mengais tanah hingga menemukan sebuah mata air yang dikenal dengan sebutan Manurake. Sebutan Manurake dalam bahasa setempat artinya ayam (ukiran ayam pada kentikaf). Kedua, ukiran motif yang melambangkan kebudayaan masyarakat pada kain tenun khas daerah Babotin. Ketiga, ukiran bunga hanya memberikan variasi pada kentikaf.

Data hasil penelitian konsep-konsep matematika yang terdapat dalam uim re'u Manunis Ka'umnais, terdapat pada tabel dibawah ini.

Tabel 1.

Rangkuman hasil penelitian

\begin{tabular}{|l|c|c|}
\hline No & \multicolumn{1}{|c|}{$\begin{array}{c}\text { Bagian/ } \\
\text { gambar }\end{array}$} & Konsep/prinsip matematika \\
\hline 1 & Atap & \\
& & $\mathrm{K}=$ jumlah semua sisi \\
& & $\mathrm{L}=1 / 2 \mathrm{x}$ jumlah sisi \\
& & sejajar $\mathrm{x}$ tinggi \\
\hline
\end{tabular}


ISSN. 2621-9832

JURNAL MathEdu (Mathematic Education Journal) http://journal.ipts.ac.id/index.php/MathEdu

Vol. 4 No. 2 Juli 2021

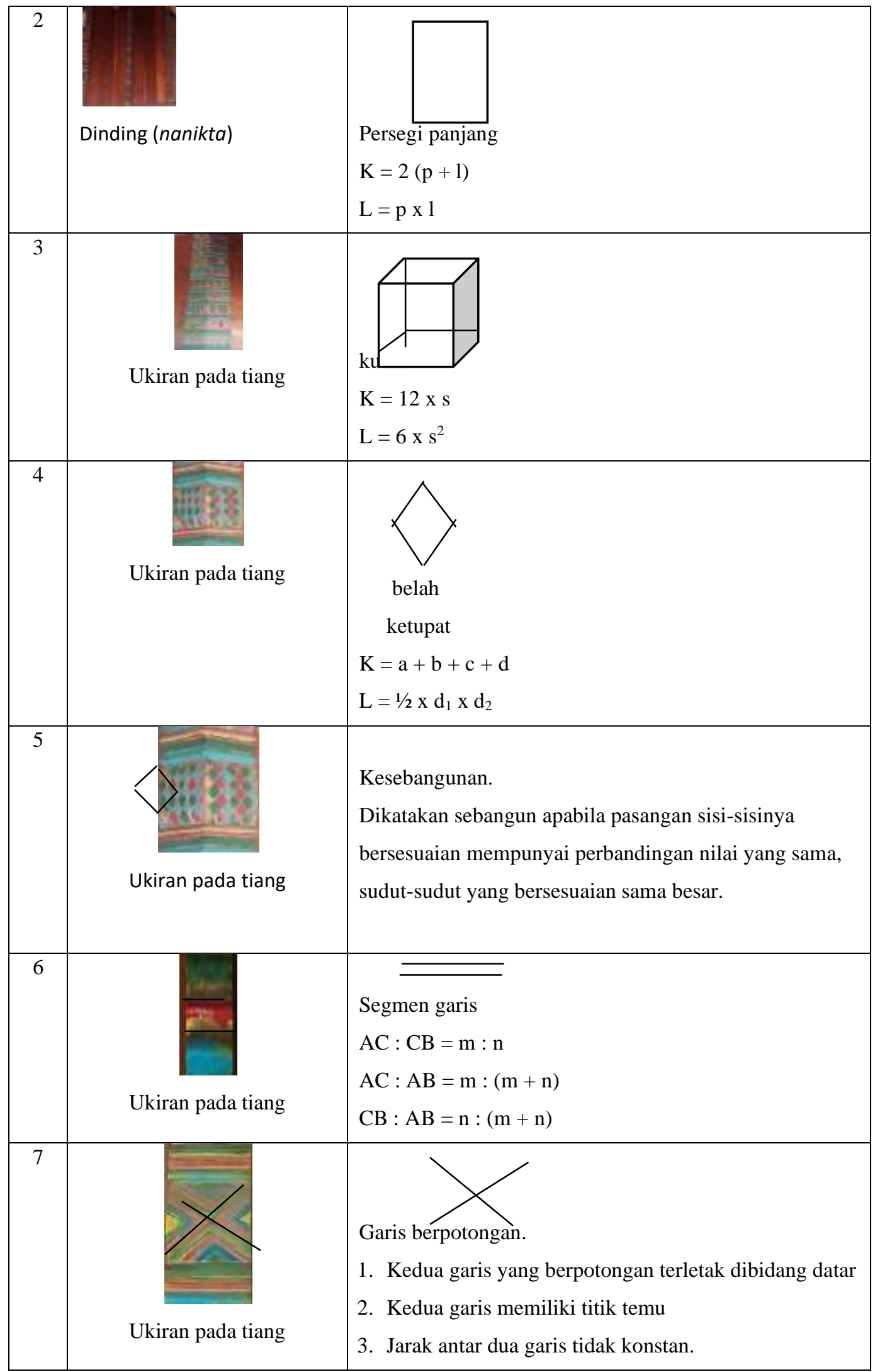


ISSN. 2621-9832

JURNAL MathEdu (Mathematic Education Journal) http://journal.ipts.ac.id/index.php/MathEdu

Vol. 4 No. 2 Juli 2021

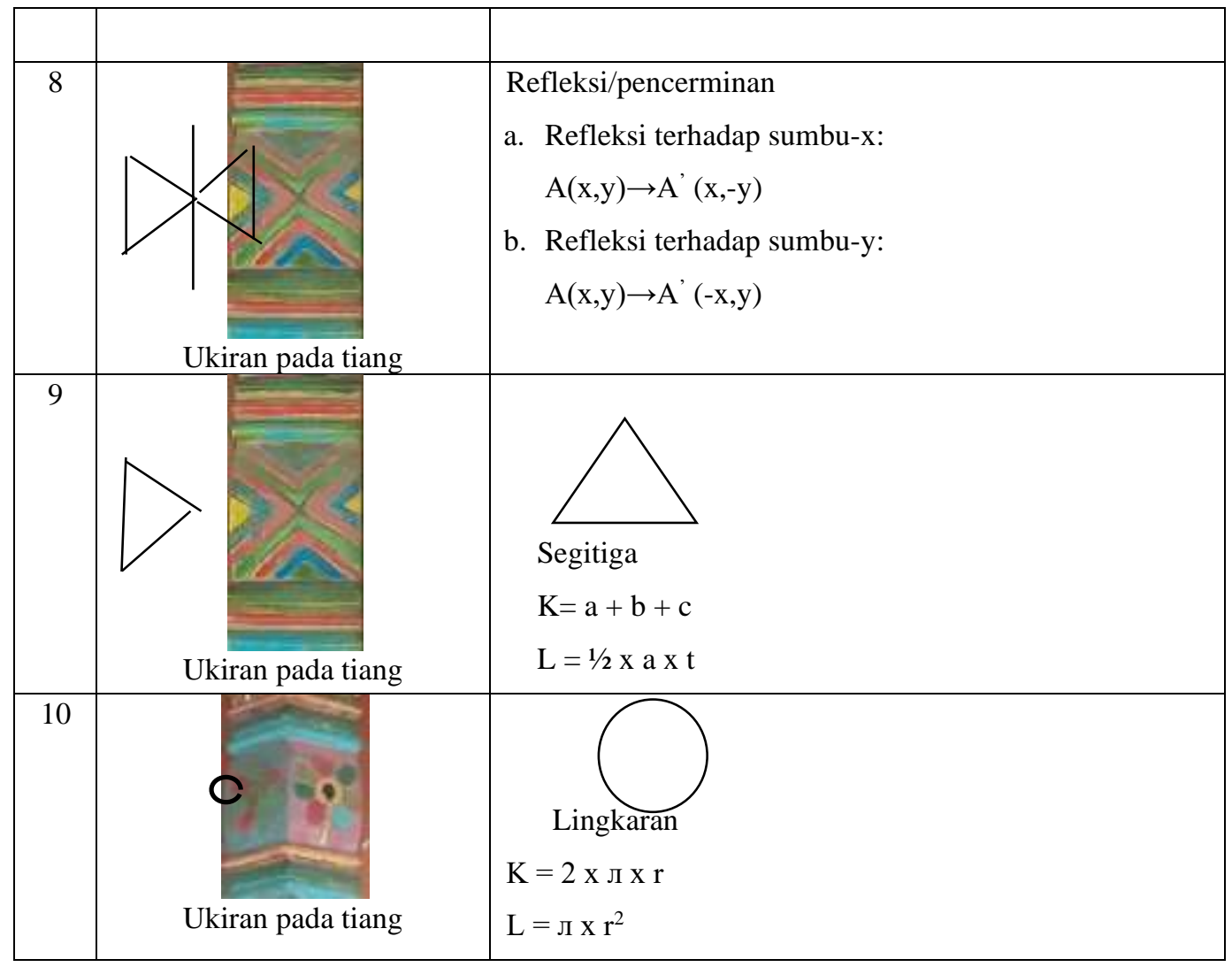

\section{PENUTUP}

\section{Kesimpulan}

Berdasarkan hasil dan pembahasan yang dipaparkan sebelumnya, dapat disimpulkan bahwa konsep matematika yang ditemukan dalam uim re' $u$ Manunis Ka'umnais antara lain:

1. Limas segiempat berbentuk trapesium yang ditemukan pada atap uim re'u Manunis Ka'umnais.

2. Bangun datar berupa persegi Panjang, belah ketupat, segitiga dan lingkaran yang ditemukan pada uim $r e$ 'u Manunis Ka'umnais.

3. Bangun ruang berupa kubus yang ditemukan pada ornament uim re'u Manunis Ka'umnais.

4. Garis, kesebangunan dan refleksi/pencerminan yang ditemukan pada ornamen uim re'u Manunis Ka'umnais.

\section{Saran}

Data-data yang terdapat dalam penelitian ini masih sangat terbatas karena itu peneliti menyarankan agar ada peneliti lanjutan.

\section{DAFTAR PUSTAKA}

Amsikan, S. \& Nahak, S. (2017) Hubungan Konsep Ruang Ume Kbubu Desa Kaenbaun Kabupaten Timor Tengah Utara Dengan Konsep Geometri. Prossiding KNPMP II. Surakarta: UMS.

Bramasti, R. (2012). Kamus Matematika. Surakarta: Aksarra Sinergi Media.

D'Ambrosio, U. (1997). ethnomathematics and its place in the history and pedagogy of mathematics. Ethnomathematics: Challenging Eurocentrism in mathematics education, 13-24. 
ISSN. 2621-9832

JURNAL MathEdu (Mathematic Education Journal) http://journal.ipts.ac.id/index.php/MathEdu

Vol. 4 No. 2 Juli 2021

Deda, Y. N. \& Amsikan, S. (2019) Geometry Concept on the Motifs of Woven Fabric in Kefamenanu Community. Journal of Research and Advances in Mathematics Education, 4(1) 1-12.

Funan, F. X., \& Mamoh, O. (2019). Eksplorasi Etnomatematika Uem Le'u Insana Dalam Kaitannya Dengan Konsep Geometri. range: Jurnal Pendidikan Matematika, 1(1), 63-75.

Hasratuddin, P. M. S. (2014). Pembelajaran Matematika Sekarang Dan Yang Akan Datang Berbasis Karakter. Jurnal Didaktik Matematika, l(2).

Munawwaroh, I. (2016). Etnomatematika pada Transaksi Jual Beli yang Dilakukan Pedagang Sayur dalam Masyarakat Madura di Paiton Probolinggo.

Nur, R. K. (2015). Eksplorasi Etnomatematika Masyarakat Suku Madura di Situnondo. Artikel Ilmiah Mahasiswa, 2(1), 1-4.

Putri, L. I. (2017). Eksplorasi etnomatematika kesenian rebana sebagai sumber belajar matematika pada jenjang MI. Jurnal Ilmiah Pendidikan Dasar, 4(1).

Rachmawati, I. (2012). Eksplorasi etnomatematika masyarakat Sidoarjo. Ejournal Unnes, 1(1).

Richardo, R. (2017). Peran ethnomatematika dalam penerapan pembelajaran matematika pada kurikulum 2013. LITERASI (Jurnal Ilmu Pendidikan), 7(2), 118-125.

Sumardyono, S. P. (2004). Karakteristik Matematika Dan Implikasinya Terhadap Pembelajaran Matematika. Yogyakarta: Pusat Pengembangan Penataran Guru Matematika.

Tandililing, P. (2015). Etnomatematika Toraja (Eksplorasi Geometris Budaya Toraja). Jurnal Ilmiah Matematika dan Pembelajarannya, 1 (1).

Tarigan, Daitin. (2006). Peningkatan Pemahaman Bentuk Geometri Melalui Pembelajaran Berbasis Multimedia Pada Anak Kelompok B Tk Kklkmd Kuwon Bambanglipuro Batul. Skripsi. Pendidikan prasekolah dan sekolah dasar, fakultas ilmu Pendidikan. Universitas Negeri Yogyakarta.

Wahyuni, A., Tias, A. A. W., \& Sani, B. (2013, November). Peran Etnomatematika Dalam Membangun Karakter Bangsa. In Makalah Seminar Nasional Matematika dan Pendidikan Matematika, Prosiding, 